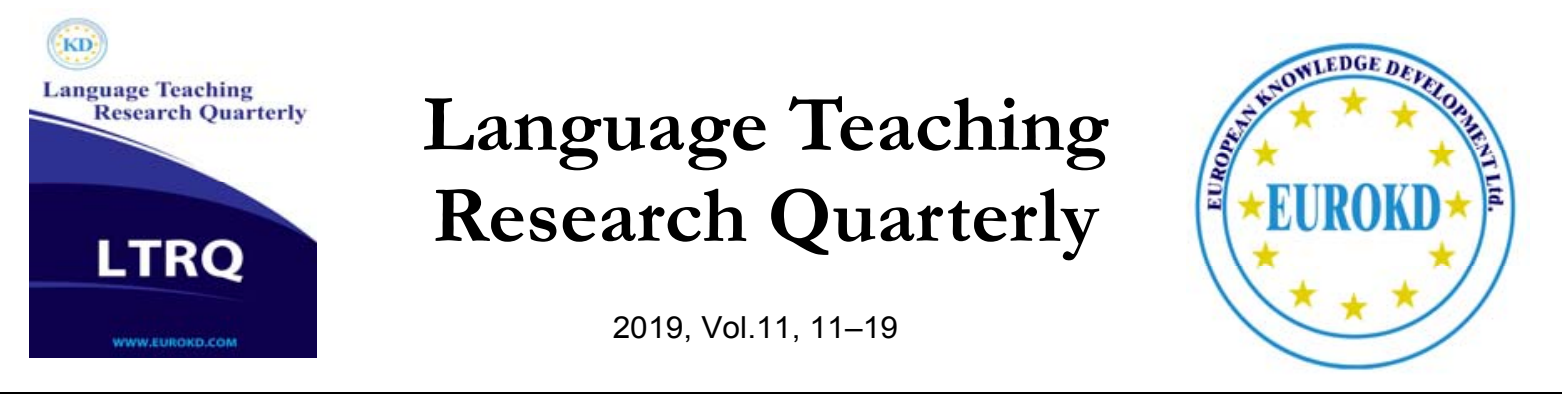

\title{
The Role of Instruction: An Update
}

\author{
Alessandro Benati \\ American University of Sharjah, UAE
}

Received 02 May 2019 Accepted 10 July 2019

\begin{abstract}
Does instruction make a difference? This was the original question of a paper written by Michael Long (1983) in the 80 s. Since then, scholars and practitioners have been debating on whether instruction makes a difference in the acquisition of language properties such as morphology and syntax. Contemporary theories have addressed this question by taking different positions around the role and effects of instruction. Researchers have investigated the effects of a number of different instructional treatments (e.g., textual enhancement, processing instruction, recasts). Overall, the main findings from empirical research on the effects of instruction seem to indicate that there are two main positions: (i) instruction has a limited and constrained role; (ii) instruction might have some beneficial effects (not on the route but on the rate of acquisition). Several key questions (VanPatten, Smith, \& Benati, 2019) have been raised in this field about the nature and role of instruction and on what we really measure with instruction (explicit or implicit knowledge?).
\end{abstract}

Keywords: Instruction, Explicit Knowledge, Implicit Knowledge

\section{Keynote Speech}

What are the Main Contemporary Theories have to Say about the Role of Instruction?

The Monitor Theory (Krashen, 1982, 2009) argues that instruction plays a limited role in second language acquisition. Krashen suggests that L2 learners acquire language mainly through exposure to comprehensible and message-oriented input. Based on empirical findings, The Monitor Theory also indicates that instruction is constrained by the fact linguistic features are acquired in a fixed and predicted order. For example, morphological features such as the 
progressive -ing in English is acquired (no matter the learner's L1) before the regular past tense ed, or irregular past tense forms, which is acquired before third-person singular -s. Instruction is therefore constrained by universal and predictable orders of acquisition. L2 learners acquire morphemes (e.g. verb inflections) in a certain order over time.

Universal Grammar Theory (White, 2003, 2015) views language as an abstract and complex system. Although many aspects of language are acquired by interaction with input (e.g. syntax, morphology, lexicon), one exception are those aspects of language that are universal and built in prior to exposure to the input language. All humans have universal features of language which constraint the acquisition of grammar. For example, sentences have underlying hierarchical structure consisting of phrases (e.g. Noun phrase, Verb phrase) which require a 'head' and a 'complement'. This information is built into L2 learners' internal system as they make use of the input to process any possible variations in the target language. Instruction has no effects on this subconscious knowledge.

Processability Theory (Pienemann, 1998; Pienemann \& Lenzing, 2015) argues that L2 learners acquire single structures (i.e. negation, question formation) through predictable stages. According to the Processability Theory, instruction is constrained by these developmental stages, and L2 learners follow a very rigid route in the acquisition of grammatical structures (e.g. word order, negation, question formation). Research on instruction and ordered development indicated that instruction does not alter ordered development in any significant way.

Input Processing Theory(VanPatten, 2004, 2015) refers to how L2 learners initially perceive formal features of language input, and the strategies or mechanisms that might guide L2 learners in processing them. L2 learners process input for meaning (words) before they process it for form (grammatical features). L2 learners seem to parse sentences by assigning subject or agent status to the first noun or pronoun they encounter in a sentence. These default processing strategies cause a delay (processing constraints) in the acquisition of formal properties of the target language. According to this theory and its research findings, instruction might be beneficial if it manipulates input so that L2 learners process grammar more efficiently and accurately. L2 learners should be exposed to meaningful input that contains many instances of the same grammatical meaning-form relationship (e.g. verb ending -ed encodes a past event). Instruction (processing instruction) should be designed to circumvent default processing strategies and replace them with appropriated ones.

Interaction hypothesis (Gass \& Mackey, 2015) considers the fact that comprehensible input might not be sufficient to develop native-like grammatical competence and L2 learners also need comprehensible output.Learners should be involved in meaningful learning tasks where they have opportunities to communicate and negotiate meaning. Instruction might be beneficial if it is provided by enhancing the input through the use of different techniques (e.g. input enhancement, and in particular textual enhancement). It might have a facilitative role in helping learners pay attention (noticing) to the formal properties of a targeted language without the need of metalinguistic discussion. 
Skill-Learning Theory (DeKeyser, 2015) views second language acquisition as a process which entails going from controlled mode (declarative knowledge) to automatic mode (procedural knowledge) through repeated practice. According to this theory, L2 learners need to be taught explicitly and need to practice the various grammatical features and skills until they are well established (fluency). Instruction is beneficial when it helps explicit knowledge to become proceduralized.

Sociocultural Theory (Lantolf, Thorne, \& Poehner, 2015) regards instruction as crucial to L2 development. The theory suggests that during instruction (metalinguistic and explicit in nature), awareness of the structure and function of language is developed by using it socially. The environment provides the context and assists in the understanding of grammatical properties of the language.

An overall review of the main contemporary theories and empirical research on the role of instruction is second language acquisition leads to the following conclusions:

- Instruction does not alter the route of acquisition (i.e., acquisition orders and developmental sequences). There are no empirical studies showing that instruction alter the order/sequence of acquisition;

- Instruction as input manipulation can facilitate language processing;

- Instruction may have some beneficial effects (e.g. developing procedural knowledge, facilitating noticing and awareness) on second language acquisition.

The effects of instruction are limited and constrained by natural orders of acquisition and by L2 learner's readiness to acquire a particular structure. If, as it seems to be the case, there are no effects on instruction on the route of acquisition, what about its possible effects on the rate of acquisition? Can instruction facilitate and speed-up acquisition of the formal properties of a target language?

In the last thirty years, research on the possible effects of instruction has manly focused on measuring its immediate effects using various experimental designs. Very few studies have measured long-term effects. Overall, the main findings (see meta-analyses such as Norris and Ortega, 2009: and Spada and Tomita, 2010) indicate that there is a "possible short-term effect" of instruction on the rate of acquisition. However, these results need to be taken with caution for a number of reasons: (i) the effects of instruction measured on rate of acquisition is mostly about the development of explicit knowledge; (ii) measurements in the research on the effects of instruction often make use of tests that measure explicit knowledge. Two key questions that need to be addressed are: Does instruction foster implicit knowledge? How do we usually measure the effects of instruction?

\section{Does Instruction Foster Implicit Knowledge?}

Explicit knowledge of language is defined as conscious knowledge. It is often verbalizable knowledge about language such as 'to talk about something in the past', add -ed sound to the end of the verb such as play versus played." Implicit knowledge, is defined as unconscious knowledge and it is not verbalizable. It is the ability to understand or supply talked and not talk 
in contexts that require the past tense in English, and to do so without a conscious effort to retrieve the form.

Language teachers instruct learners about something, L2 learners practice it, and then the teachers assess them using a paper and pencil test. There are two problems with this type instruction aiming at developing explicit knowledge: (i) instruction does not correspond to the way language develop in the mind/brain; (ii) instruction does not correspond to the way learners process information. Language acquisition is about the development of implicit knowledge. Language as mental representation is too abstract and complex to teach and learn explicitly (VanPatten \& Rothman, 2014). In short, language is not the rules and paradigms that appear on textbook pages. Explicit rules and paradigm lists can't become the abstract and complex system because the two things are completely different. This implication stems from the fact that there is no internal mechanism that can convert explicit textbook rules into implicit mental representation (VanPatten, 2016).

Instruction has an effect on fostering explicit knowledge, at least in the short-term. DeKeyser (2015) argues that practice in which learners deliberately focus their attention on L2 form might help the development of a skill. Practice of the kind used in traditional instruction does little to foster the development of mental representation and tend to develop a learning-like behavior. Instruction night not have an effect on L2 learners implicit knowledge unless it is of a particular type that can facilitate acquisition (e.g. structured input practice).

VanPatten and Benati (2010:31) have argued that "L2 learners clearly create linguistic systems in an organized way that seem little affected by external forces such as instruction and correction". The acquisition of the grammatical properties of a target language is mainly implicit (VanPatten \& Rothman, 2014; VanPatten \& Benati, 2015).

L2 learners create an abstract system (mental representation) similar to the way in which L1 learners do. Instruction can be devised in a way that, on one hand, enhance the grammatical features in the input, and on the other hand, provide L2 learners with opportunities to focus on meaning. Scholars in second language acquisition have agreed that L2 learners must be exposed to input and that input must be comprehensible and meaning-bearing in order to facilitate language development. Language that learners hear and see in communicative contexts forms the data on which the internal mechanisms operate. The only effective way to facilitate language development (implicit knowledge) is the provision of good quality input.

This view about language and language development (too abstract and complex to teach and learn explicitly) has profound consequences for how we implement instruction in the language classroom. Explicit rules and paradigm lists can't become the abstract and complex language system because the two things are completely different. This implication stems from the fact that there is no internal mechanism that can convert explicit textbook rules into implicit mental. Most textbooks and many teachers continue to treat language like any other subject matter. What winds up in the human mind has no resemblance to anything on textbook pages or what teachers say. 
How do we provide effective instruction? L2 learners often expects to get presentation and explanation of grammar rules from the teacher. Language teachers often explain rules and this is followed by mechanical output practice (drills). However, let's quickly review basic facts about language and language acquisition:

- Language is abstract and complex and should not be taught and learn explicitly. There is no mechanism that turns explicit "rules" into the abstract and complex mental representation we call "language";

- Acquisition is slow and piecemeal. L2 learners don't acquire one thing and then move on to another, as suggested by typical syllabi and textbooks. L2 learners' minds are constantly working on various aspects of language simultaneously. Only over time the internal system builds up and begin to resemble the second language;

- Acquisition is stage-like and ordered. In the acquisition of any structure there are stages that all learners go through regardless of their L1. There is no evidence that stages can be skipped or orders can be altered;

- Input provides the data for acquisition. Language that learners hear and see in communicative contexts forms the data on which the internal mechanisms operate.

Input is the single most important concept in second language acquisition. Considering the limited role for instruction, language practitioners should look at devising instructional treatments that, on one hand, enhance specific grammatical features in the input, and on the other hand, provide L2 learners with opportunities to focus on meaning.

The question is to determine what type of instruction is more successful in terms of helping learners internalize the grammatical features of a target language. If we are going to instruct L2 learners on formal properties of the language in any way in the classroom, it ought to be input based and meaning oriented. This idea falls out of what we know about the nature of acquisition; that is, how it is tied to input within communicative settings and not explanation + practice. Instruction might help L2 learners to develop a good level of attainment particularly if opportunities to natural exposure are given. Instruction has a facilitative role when it is used for linguistic features, which are not too distant from the learner's current level of language development. It might have a facilitative role in helping learners to pay selective attention to form and form-meaning connections in the input. Learners make form-meaning connections from the input they receive as they connect particular meanings to particular forms (grammatical or lexical). For example, they tend to connect a form with its meaning in the input they receive (the morpheme ed on the end of the verb in English refers to an event in the past). VanPatten (2015) has indicated that L2 learners find it difficult to attend to form and meaning simultaneously with the input they receive. Therefore, learners must be trained on how to process input more effectively and efficiently so that they are in a better position to process grammatical forms and connect them with their meanings. Although, the route of acquisition cannot be altered, instruction might in certain conditions speed up the rate of acquisition and develop greater language proficiency. What are the conditions that might facilitate the speed in which languages are learned? A first condition is that L2 learners must be exposed to sufficient input. A 
second condition is that L2 learners must be psycholinguistically ready for instruction to be effective. A third condition is that instruction must take into consideration how L2 learners process input.

\section{What Effective Types of Instruction might Speed-up the Rate of Acquisition?}

Considering the limited role for instruction, researchers have investigated the effects of a number of input-based and interactional options to instruction which might help L2 learners to internalize the grammatical features of a target language.

Processing instruction (VanPatten 1996; Benati, 2017) is an instructional intervention that through the manipulation and restructuring of the input facilitates the acquisition of grammatical and syntactic features of a target language. Textual enhancement (Sharwood Smith (1993) is an instructional intervention through which the input is made more noticeable with the understanding that making certain features salient in the input might help drawing learner's attention to that specific feature. Corrective feedback refers to utterances from a language instructor or another speaker which indicates that the learner's output in not correct. Nassaji and Fotos (2011) have distinguished between two types of interactional feedback: reformulation and elicitation. Reformulations are those corrective feedback techniques such as recasts. Recast refers to an implicit technique to corrective feedback in which L2 learners are provided with the correct form

As previously stated, the role of instruction in language acquisition is limited and constrained by a number of factors e.g., orders and sequences of development, processing contrains). However, despite the fact that instruction is, for instance, not able to alter the route of acquisition, it might have some beneficial effects in terms of speeding up the rate of acquisition. Textual enhancement provides L2 learners with access to comprehensible input, positive evidence and help them to pay attention to grammatical forms in the input. Processing instruction through structure input practice helps learners to process the input correctly and efficiently, and as a result of this, the learner's intake of language input is increased. Classroom research has also indicated that it is desirable and helpful to provide corrective feedback without interrupting the flow of communication (recast).

In terms of the effectiveness of pedagogical intervention to instruction, 'it is clear that the field has slightly shifted from the more global question "Does instruction make a difference?" (Long 1983) to more specific question "Does manipulating input make a difference" (VanPatten \& Benati 2015: 52).

\section{How do We Usually Measure the Effects Instruction?}

Experimental studies on the effects of instruction have overall used the same pre and post-test design to measure the effectiveness of different pedagogical interventions on the acquisition of a variety of linguistics features (Benati \&Schwieter, 2019). In these studies if L2 learners perform better after instruction, we tend to conclude that "instruction makes a difference'. In most of the studies conducted to measure instruction, there is often a clear bias toward testing explicit 
knowledge (testing explicit rules). We say that instruction (explicit and traditional) "makes a difference" for test-taking in classrooms. There is certainly the need to carried out more research on the effects of instruction which measure implicit knowledge as opposed to explicit rules. This kind of research would also need to adopt psycholinguistics and neurolinguistics methods which capture online processing and brain/mind activities to measure implicit knowledge.

Benati (forthcoming) conducted a study to explore the effects of structured input and traditional instruction on the acquisition of English causative passive forms using online measurements (eye-tracking). Previous empirical research investigating the effects of processing instruction through offline measurements (sentence and discourse) has overall showed positive results for this pedagogical intervention. Research investigating the main factor responsible for the effectiveness of processing instruction has confirmed that it is the structured input component that is the causative factor for the positive effects of processing instruction. The main questions of this study were: (i) What are the effects of structured input and traditional instruction on accuracy when measured by an eye-tracking picture selection task? ; (ii) Would possible difference in accuracy between structured input and traditional instruction be accompanied by changes in eye-movement patterns? To provide answers to the two questions formulated in this study, one eye-tracking study was carried out. Fifty-two adult learners (aged 19-21) participated and were assigned to one of two groups: structured input $(n=26)$ or traditional instruction $(n=26)$. Neither instructional groups received explicit information. A pre and post-training design was adopted and the two groups received two different instructional treatments (structured input vs. traditional instruction). Participants were assessed through a picture selection eye-tracking task to measure accuracy and eye-movement patterns while they were processing auditory sentences. Results of the eye-tracking task indicated that the structured input group achieved significantly higher accuracy scores compared to the group receiving traditional instruction. The main findings from the present study reveal that structured input training causes a change in learners' eye-movement patterns. This type of study provides us with an appropriate implicit knowledge measurement of the effects of instruction (in this case a pedagogical intervention called structured input) on the acquisition of a formal property of the target language.

\section{Conclusive Remarks}

Since Long's original paper (Long, 1983) empirical research and contemporary theories have investigated and debated the role and nature of instruction. Research findings seem to indicate that instruction on formal features of language does not affect order and sequence in language development. However, onstruction on formal features of language might speed up acquisition. There are important factors (e.g., quality of input) that might help instruction to speed up the rate of acquisition.

We also need to consider the nature of language and the qualitative difference between explicit and implicit knowledge. Explicit rules cannot be equated to language which is an abstract and complex system. Language as mental representation is too abstract and complex to teach and learn explicitly. L2 learners create an abstract system similar to the way in which L1 
learners do. Mental representation bears no resemblance to what is traditionally taught and practiced.It builds up over time due to consistent and constant exposure to input data and interaction with universal properties.

Classroom research investigating the effects of instruction is biased toward the testing of explicit knowledge. Future research would need to consider the following:

(i) The nature and characteristics of implicit knowledge and how it can be measured;

(ii) The use of appropriate pedagogical interventions (e.g. input and processing-based) that can have an effect on L2 learners' implicit knowledge system.

There is an overwhelming bias toward testing explicit knowledge in the research on the effects of instruction. The main finding of this research is that instruction makes a difference in traditional pencil and paper tests. Researchers must begin to measure implicit knowledge. Practitioners must foster the development of language and instead of developing in L2 learners a learning-like behavior, they must use pedagogical interventions that facilitates language processing, and the development of implicit knowledge.

Classroom research investigating the effects of instruction, like in the case of the empirical study mentioned in this paper, must make use of on-line measurements. These methodological tools (self-paced listening and reading, eye-tracking, ERPs) might offer us the possibility of more fine-grained information and analysis about moment-by-moment sentence comprehension and a reliable measurement of implicit knowledge.

\section{References}

Benati, A. (2017). Classroom-oriented research: Processing Instruction (findings and implications). Language Teaching, 1-17. 10.1017/S0261444817000386

Benati, A., Schwieter, J. (2019). Pedagogical interventions to L2 grammar instruction. In J. Schwieter \& A. Benati, A. (Ed.). The Cambridge Handbook of Language Learning (pages forthcoming). Cambridge: Cambridge University Press.

Benati, A. (forthcoming). The effects of structured input and traditional instruction on the acquisition of the English causative passive forms: An eye-tracking study measuring accuracy in responses and processing patterns. Language Teaching Research.

DeKeyser, R. (2015). Skill Acquisition Theory. In B.VanPatten \& J. Williams, J. (Eds.), Theories in second language acquisition ${ }^{\text {nd }}$ edition (94-112). New York: Routledge.

Gass, S., Mackey, A. (2015). Input, interaction and output in second language acquisition. In B.VanPatten \& J. Williams, J. (Eds.), Theories in second language acquisition $2^{\text {nd }}$ edition (180-206). New York: Routledge.

Krashen, S. (1982). Principles and practice in second language acquisition. London: Pergamon.

Krashen, S. (2009). The comprehension hypothesis extended. In T. Piske \& M. Young-Scholten (Eds.), Input matters (81-94). Bristol: Multilingual Matters.

Lantolf, J., Thorne, S., Poehner, E. (2015). Sociocultural theory and second language development. In B.VanPatten \& J. Williams, J. (Eds.), Theories in second language acquisition $2^{\text {nd }}$ edition (207-226). New York: Routledge.

Long, M. (1983). Does second language instruction make a difference? TESOL Quarterly, 17, 359-382.

Nassaji, H., and Fotos, S. (2011). Teaching grammar in second language classrooms. New York: Routledge.

Norris, J., Ortega, L. (2000). Effectiveness of second language instruction: A research synthesis and quantitative meta-analysis. Language Learning, 50, 417-528. 
Pienemann, M.(1998). Language processing and L2 development. New York: Benjamins.

Pienemann, M., Lenzing, A. (2015). Processability theory. In B.VanPatten \& J. Williams, J. (Eds.), Theories in second language acquisition2 ${ }^{\text {nd }}$ edition (159-179). New York: Routledge.

Sharwood Smith, M. (1993). Input enhancement in instructed SLA: Theoretical bases. Studies in Second Language Acquisition, 15, 165-179.

Spada, N., Tomita, Y. (2010). Interactions between type of instruction and type of language feature: A metaanalysis. Language Learning, 60, 263-308.

VanPatten, B. (1996). Input Processing and Grammar Instruction: Theory and Research. Norwood, NJ: Ablex.

VanPatten, B. (2004). On the Role(s) of Input and Output in Making Form-Meaning Connections. In B. VanPatten, J. Williams, S. Rott, \& M.Overstreet (Eds.), Form-Meaning Connections in Second Language Acquisition (2947). Mahwah, NJ: Erlbaum.

Van Patten, B. (2015). Input processing in adult SLA. In B.VanPatten \& J. Williams, J. (Eds.), Theories in second language acquisition $2^{\text {nd }}$ edition (113-135). New York: Routledge.

VanPatten, B. (2016). Why explicit knowledge cannot turn into implicit knowledge. Foreign Language Annals, 49, 650-657.

VanPatten, B., Smith, M., Benati, A., (2019). Key Questions in Second Language Acquisition: An Introduction. Cambridge University Press.

VanPatten, B. Benati, A. (2015). Key terms in second language acquisition, $2^{\text {nd }}$ edition. London: Bloomsbury Publishing.

VanPatten, B. Benati, A. (2010). Key terms in second language acquisition, $1^{\text {st }}$ edition. London: Continuum.

VanPatten, B., Rothman, J. (2014). Against rules. In A. Benati, C. Laval, \& M. Arche, The grammar dimension in instructed second language learning (15-35). London: Bloomsbury.

White, L. (2003). Second language acquisition and universal grammar. Cambridge: Cambridge University Press.

White, L. (2015). Linguistic theory, universal grammar, and second language acquisition. In B.VanPatten \& J. Williams, J. (Eds.), Theories in second language acquisition $2^{\text {nd }}$ edition (34-53). New York: Routledge. 